\title{
Una lectura posmoderna de Cielos de la Tierra de Carmen Boullosa: recuperación de la memoria, la historia y la utopía a través de la escritura
}

\author{
ILIANA AlCÁNTAR*
}

Dudé de mi propia existencia. D udé de la Tierra, dudé
de la destrucción, dudé de la naturaleza. D udé de la lengua.

(Cielos dela Tierra 309)

Resumen:

Este artículo explica la manera en que Cielos de la Tierra de Carmen Boullosa pertenece a un modelo de literatura posmoderna cuyas características son la autorreflexividad, la metaficción, la historiografia, la subjetividad y la utopía. A través del análisis textual se deduce un juego de transposiciones autorales, en donde los relatos predominantes tienen como objetivo recuperar la memoria por medio de la reconstrucción de la historia. En este estudio se analizan los rasgos principales de cada una de las características posmodernas que muestra esta novela de Boullosa; específicamente se analizan los elementos posmodemos que se manifiestan en tres entidades que forman parte de una unidad. Los tres personajes principales de la novela comparten la necesidad de salvar la memoria, la historia y la utopía, estos personajes llevan a cabo su labor a través de la escritura. D esde diferentes espacios, épocas e idiomas logran crear un texto dialógico.

Palabras clave:

Novela mexicana contemporánea, literatura mexicana contemporánea, narrativa mexicana, literatura escrita por mujeres, posmodernidad, Carmen Boullosa. 
Ofrecer la posibilidad de una lectura posmoderna de Cielos de la Tierra no corresponde al afán de integrarme a un debate que un término tan controversial como la posmodernidad conlleva. Más bien, se trata de un intento por dilucidar en qué manera esta obra narrativa de Boullosa se conforma a un modelo de la literatura posmoderna, para lo cual utilizo y baso mis premisas en los trabajos de aquellos que han llevado el tema de la literatura posmoderna a Latinoamérica, como es el caso de Linda Hutcheon y Santiago JuanNavarro. En este trabajo me propongo hacer un análisis textual de Cielos de la Tierra al tiempo que establezco una correspondencia entre la novela y las características posmodernas de la literatura como lo son la autorreflexividad, la metaficción, la historiografía, la subjetividad y la utopía.

Cielos de la Tierra es sin duda alguna una novela con tintes históricos, y también podría designarse en lo que Seymour Menton acuña como nueva novela histórica. ${ }^{1}$ Escrita en una estructura que semeja las cajas chinas o las matrioshkas, la novela va develando capas que a su vez van descubriendo los tres diferentes personajes/ autores de la misma. El personaje más ajeno a nuestra experiencia cotidiana -y real- es Lear, sobreviviente de la destrucción total del mundo, quien habita una sociedad futura llamada L'Atlàntide y cuyo gobierno está por abolir la memoria humana después de haber desterrado el lenguaje tanto oral como escrito. Lear es paleógrafa y secretamente estudia el manuscrito de Estela Díaz, habitante del México de los años noventa, quien a su vez realiza estudios de pa-

${ }^{1}$ Según Seymour Menton existen seis características que la novela debe reunir (aunque no todas se encuentran siempre) para poder ser catalogada como nueva novela histórica. Estas son: la subordinación de la recreación mimética de un periodo histórico a través de tres ideas filosóficas de Borges; la distorsión consciente de la historia; el uso de personajes históricos famosos como protagonistas; la metaficción; la intertextualidad; los conceptos bajtinianos de dialogismo, lo carnavalesco, parodia y heteroglosia. Como es fácil observar, los rasgos atribuidos a la novela posmoderna coinciden con varias de las características establecidas por Menton. Para un estudio más extenso del tema véase su libro L atin A merica's $\mathrm{N}$ ew H istorical $\mathrm{N}$ ovel. 
leografía en el manuscrito de Hernando de Rivas, quien escribe en latín la crónica que narra su paso por el Colegio de Santa Cruz de Tlatelolco, en la Nueva España.

Cielos es entonces un juego de trasposiciones autorales, en donde los relatos predominantes de Lear y Hernando - cuyo objetivo es recuperar la memoria por medio de la reconstrucción de la historia- están unidos por el hilo narrativo de Estela, quien a pesar de ser también personaje-autor, se ve relegada por los discursos de los otros dos. ${ }^{2}$ La empresa de Hernando es más subjetiva y cuenta con motivos ulteriores; a él principalmente le importa expresar el sufrimiento que ha sido su vida y ofrecer su visión de las consecuencias de la imposición de la colonia española. Lear por su parte es más ambiciosa; por medio de la reconstrucción de los manuscritos de Estela y Hernando pretende aferrarse a los últimos vestigios de la memoria del pasado que conoce, pero que está por perder gracias a las ordenanzas de su avanzada comunidad.

Según Juan-Navarro en su libro A rchival Reflections las dos características que distinguen a la narrativa posmodema como tal son la autorreflexividad (self-reflexivity), y el revisionismo histórico o la narrativa historiográfica. A pesar de que el autor basa su estudio en algunas novelas históricas escritas en Latinoamérica y Estados Unidos en los años setenta, utilizo los parámetros de su texto crítico por ser aplicables a la novela de Boullosa en ambas instancias.

Para Juan-Navarro la autorreflexividad es una tendencia propia de la narrativa contemporánea que tiene como característica enfocarse en su propio proceso (40); y ya en novelas como Rayuela, E l libro vacío y E l jardín de al lado, hemos podido explorar el proceso de la metaficción en la elaboración del artificio. Sin embargo, es en Cielos de la Tierra que esta práctica se ve llevada a su máxima expresión por contar con seis escritores que declaran ser los creadores

${ }^{2}$ En comparación con los otros dos personajes-autores, Estela es la que menos participa en la narrativa, y sirve más que nada de vínculo entre los mundos de Hernando y Lear. 
del mismo texto, y quienes a lo largo de la novela reafirman el proceso metanarrativo.

Desde el inicio de Cielos, la misma Boullosa alude al lector y lo previene: "Esta novela no es de autor, sino de autores. En sus páginas hay tres personajes que confiesan confesar, y habemos dos que confesamos haberla escrito" (9). En efecto, luego que Boullosa dedica su obra, "el segundo que confiesa haberla escrito", Juan Nepomuceno Rodríguez Álvarez irrumpe con una "Nota del autor" para reafirmar la premisa de Boullosa. A su vez, Juan Nepomuceno es sumamente perspicaz al notar que: "La novela es diálogo y es unidad" (13). Cielos de la Tierra ejemplifica un dialogismo en el que sus tres personajes-narradores principales, Lear, Estela y Hernando entablan un intercambio de voces a través del tiempo, el espacio y el lenguaje.

Sin duda el recurso más importante del que se vale la novela autorreflexiva, según Juan-Navarro, es la metaficción. A demás de hacer obvio ante el lector el proceso creativo, el hecho de exponer la autorrepresentación como parte de la estructura de la novela ayuda a borrar las líneas entre el arte y la teoría, y la ficción y la realidad (41). ${ }^{3}$ Es en este entorno posmoderno donde las fronteras delimitantes entre realidad y ficción son cada vez más imperceptibles, la creación de la obra literaria requiere una participación más activa del lector, ya que éste se ve aludido a cada momento por los narradores, quienes a su vez interrumpen el relato para recordarnos su quehacer: la creación del artificio.

Ahora bien, el proceso metaficcional en Cielos de la Tierra puede ser rastreado principalmente a través de los tres personajes-narradores. Cada uno de ellos suspende su papel preponderante de escri-

${ }^{3}$ Una de las definiciones que utiliza Juan-Navarro en su libro para explicar el término de metaficción es la de Patricia Waugh quien dice: "Metafiction is a term given to fictional writing which self-consciously and systematically draws attention to its status as an artifact in order to pose questions about the relationship between fiction and reality" (41). 
tor para llamar la atención del lector a su oficio. Hernando, Estela y Lear incesantemente y sin dar tregua nos recuerdan que estamos siendo testigos de su labor, y al hacerlo nos recuerdan nuestra propia función de lectores, lo cual enfatiza nuestro significativo papel en el mismo proceso de la creación. Para Hutcheon este aspecto en las obras metaficcionales es una paradoja, pues advierte: "They invite the reader to participate in the creation of meaning, while simultaneously distancing that reader through their very selfreflexiveness" (A rchival Reflections 42).

En las pocas ocasiones que Estela tiene oportunidad de abrir sus propios cestos, ${ }^{4}$ su relato se ve coartado por sus desvaríos anecdóticos, prolongando su narración al entrar en pormenores sobre ella misma, su abuela y su bisabuela. D esde el inicio Estela se toma una licencia poética al expresar: "A manera de prefacio de la traducción del manuscrito del siglo XVI que llegó a mis manos, firmado por 'Hernando de Rivas, exalumno del Real Colegio de Santa Cruz de Tlatelolco', incluiré algunas palabras mías para explicar mi relación con éste" (33). No obstante, éstas terminan siendo más que algunas palabras. A partir de entonces veremos la inserción de la experiencia personal de Estela donde cuenta su pasado, su presente y hasta sus sueños.

Ya sea en forma de narrativa, como una película, o videoclips televisivos, la experiencia de Estela irrumpe e interrumpe la traducción de la crónica de Hernando para al final dejar definitivamente inconclusa la gran historia, la que habría de arrojar luz sobre cómo se sucedió el fin de la humanidad, o por qué le importa tanto el manuscrito de Hernando (33), lo cual nunca nos lo dice. Lo que sí nos dice a los lectores es que actuará arbitrariamente y que si se toma la libertad de apropiarse de la historia de este indígena de

${ }^{4}$ Los cestos ("kestos" en el texto) equivalen a los capítulos de un libro. Estos cestos impuestos por Lear como método de organización incluyen el nombre del personaje-narrador en turno. La necesidad de abrir y cerrar cada cesto al inicio y término de cada capítulo reafirma la idea de la estructura de la novela similar al concepto de las cajas chinas o muñecas rusas. 
noble ascendencia es porque siente que le pertenece. $\mathrm{Y}$ al hablarnos de la traducción del manuscrito de su querido Hernando que eventualmente realizará nos dice directamente: "No he pensado en ti, lector, cuando la he escrito. Lo he hecho para mí. [... ] Entonces lo que habrá de hacerse es tirar las páginas que de mi propia invención he escrito, y escuchar la confesión que empieza en la siguiente hoja" (67).

Por otra parte, Hernando, al igual que Estela, se declara desde un principio autor absoluto del texto que estamos leyendo: "A riesgo de escribir disparates, pues soy persona sin lumbre de fe, contaré aquí la historia que creo preciso anotar para que no desvanezca del olvido" 5 (69). De la misma forma que Estela, Hernando se deja inundar por los recuerdos, lo cual le complica la tarea de llevar a cabo su misión: "Pasan y pasan los días y vuelven a pasar atados de veinte en veinte, y yo, con la lengua desatada, de línea en línea voy brincando sin entrar de lleno a mi historia" (257); o cuando escribe, "D emuestro cada día en la lenta manera de narrar mi historia que las piernas firmes [...] no me permiten ir al paso de los recuerdos" (263). Pero en cada momento que Hernando divaga, que se aparta de su objetivo, él también hace partícipe al lector de su desvarío, y se vuelve a reprender por no avanzar en la escritura de lo que sí intenta plasmar, aunque con dichas divagaciones consiga llenar las páginas de otra historia más interesante: la suya. Y casi sin darse cuenta y en actitud reflexiva nos dice a los lectores: "D esde este pedazo les cuento mi historia, pues eso soy, eso queda de mí" (357). La misma Lear es quien mejor lo entiende, o le cree cuando exclama: "Sigo con mi Hernando, que sabio quiso hacer de palabras lo que fue su vida real" (118).

Lear, la habitante de los Cielos de la Tierra, tampoco se aparta de las costumbres literarias de Hernando y Estela. A medida que va-

${ }^{5}$ Sin embargo, lo que empezamos a leer es el primer cesto (o capítulo) en la vida de Hernando gracias a la traducción del latín al español que realiza Estela. 
mos conociendo L'Atlàntide y sus habitantes, Lear, 24, o Cordelia ${ }^{6}$ reflexiona sobre su acción de transcribir el manuscrito de Hernando por medio de la traducción de Estela. Aunque la distancia entre Hernando y ella es mayor (por el idioma y el tiempo), Lear encuentra en Hernando el refugio que L'Atlàntide debía ser y no lo es. Con el paso del tiempo, Lear se separa por completo de su entorno y sus compañeros, y hace de los textos de Hernando y Estela su universo, para al final llegar a la enajenación total: "Es cierto que aquello que habita un libro es un territorio verdadero. Éste en el que estoy no lo es más" (368). Lear, al repudiar su comunidad idílica convertida en pesadilla busca habitar el mundo de los libros, y empero su desencanto con su medio y los otros habitantes de L'A tlàntide, asume su rol de narradora y nos dice: "Si quisiera reseñar cuanto hacen [...] tendría que seguirlos. [... ] Seguirlos mientras escribo aquí. Las palabras son más lentas que sus vertiginosos actos, pero podría resumir sus acciones. Para convertirme en su cronista tendría que laborar solamente para ellos" (361).

Para concluir el aspecto de la autorreflexividad por medio de la metaficción, quiero mencionar que en este intenso mise en abyme, juego de espejos, autores y relatos superpuestos, el aspecto lúdico alcanza su punto máximo cuando nos enteramos al final que existe un sexto autor, un narrador inesperado que irrumpe el entorno narrativo de Boullosa, Juan Nepomuceno, Lear, Hernando y Estela. El último cesto de Estela es interrumpido por una nota que no pertenece a ella, ni a Hernando ni a Lear, pero cuyo mensaje sorprende a ésta y sólo atina a balbucear: "No acierto a qué decir. [...] La nota de este hombre, a quien desconozco por completo, viene a robarme a mi Hernando" (367). Así, caemos en cuenta que uno de los tejedores permanecía latente, y que éste ayuda a concluir la creación del artificio.

${ }^{6}$ Lear cambia de nombre sin explicación o motivo alguno. Tal vez sea un indicio que los nombres y el género ya no importan, pues el lenguaje en L'Atlàntide ha sido abolido del todo. 
Para abordar el elemento de la metaficción historiográfica es necesario recurrir una vez más a Hutcheon, quien considera esta característica como la más representativa de la novela posmoderna, noción que contesta Juan-Navarro por excluir obras que no son historiográficas pero que han contribuido al debate del posmodernismo y entre cuyos autores podemos mencionar a Severo Sarduy, Guillermo Cabrera Infante y Salvador Elizondo, entre otros (A rchival Reflections 33). Para Hutcheon, estos textos representativos de la metaficción historiográfica responden a un impulso paradójico:

They purport to be self-referential but they are presented ultimately subject to history. [...] No matter how self-referential and reflexive they might seem, these works end up asserting their subjection to history, but history itself is depicted as equally unable to escape from the limitations of all cultural constructions. (A rchival Reflections 33)

Por su parte Juan-Navarro propone el elemento historiográfico como una alternativa a la metaficción historiográfica de Hutcheon; según Juan-Navarro, la novela posmoderna además de ser autorreflexiva por naturaleza, se caracteriza en ocasiones por la revisión histórica. Ciertamente Cielos de la Tierra está cargada de fuertes referencias históricas en los tres planos del pasado, presente y futuro. En las tres narraciones de Hernando, Estela y Lear abundan los acontecimientos, fechas, lugares, escritores, poetas, obras, y personajes reales. A veces el uso excesivo de datos históricos hace dudar al lector de la veracidad de lo que lee, y el discurso histórico como conjunto totalizador pierde toda validez, ya que la verdad ya no es sólo una, sino muchas, y estas verdades tienen que ser revisadas y revaloradas dentro del marco de referencia que es la novela.

A propósito de estas verdades, a Hernando le inquieta sobremanera lo fidedigno de su relato, y le revela al lector su mayor preocupación: el propósito por no distorsionar ni modificar su historia, aunque ésta no sea buena, y clama su apego por la veracidad de los hechos, diciendo: "La verdad no me favorece, pero aunque no lo 
haga, verdad es, y aquí debo contarla" (82). Curiosamente su ansiedad recurrente por la autenticidad de los datos lleva al lector a poner en tela de juicio lo que Hernando relata. Tan empeñado está él en no tergiversar la realidad que su intranquilidad parecería más bien tratar de ocultar un sentimiento de culpa.

El inestable estado emocional de Hernando se nos revela a lo largo de su relato, y es clave para explicar los altibajos que éste sufre. En ocasiones se confiesa dudoso de su misma memoria: "Lo platico porque temo que todo esto que aquí he ido escribiendo no fue así, que el resplandor de un hecho cierto que no alcanzó mi conciencia a mirar me lo hizo creer por verdadero" (312). Y en otra instancia se declara incapaz de distinguir la realidad de la imaginación, poniendo en duda la veracidad de lo que ha narrado: "Q ue yo bordo, interpreto, explico alrededor de lo que no ocurrió, que el reflejo de algo que no acerté a comprender dejó marcado en mi imaginación su paso, como si fuera la presencia de algo real, moviéndose a la compasión y el llanto" (312).

Si Hernando "miente" o no, no lo sabemos, pero lo curioso es que él es el personaje que más oportunidad tiene de manipular datos, fechas, lugares y personajes históricos. Es también Hernando quien oculta y engaña su verdadero manuscrito a los demás frailes, y es Hernando quien ha vivido una existencia de suplantación, quien ocupó un lugar en nombre de otro. ${ }^{7}$ Triste, Hernando se lamenta: "iQué sucesión de no míos, de míos ajenos, le fueron asignados en sus primeros años a mi torpe vida!" (268). Resulta sumamente sospechoso entonces que quien no ha conocido otra experiencia sino la de la impostura, tenga una desmedida afición por ser fidedigno. Hernando fracasa como prototipo del historiador, quien además de conocer la verdad, no duda nunca de ella.

${ }^{7}$ Hernando desde su infancia vive una vida de impostura, y entra precisamente al Colegio de Santa Cruz de Tlatelolco suplantando a Carlos O metochtzin, hijo de un pariente influyente de su madre, cuya familia no quiso "sacrificarlo" entregándoselo para su educación cristiana a los frailes franciscanos. 
Otro rasgo particular de la ficción posmoderna es el aspecto de la subjetividad que elabora Linda Hutcheon cuando asegura

As D errida insists: "The subject is absolutely indispensable. I don't destroy the subject; I situate it.' And to situate it, as postmodernism teaches, is to recognize differences of race, gender, class, sexual orientation, and so on. To situate is also both to acknowledge the ideology of the subject and to suggest alternative notions of subjectivity. (159)

Podemos aseverar que tanto Estela como Hernando precisamente reclaman una notoriedad que les es negada en la historia oficial. El relato de sus vidas, demasiado ordinario para transferirse a los anales históricos, no se propone contar grandezas. Los tres personajes, podríamos decir, son minorías, artistas clandestinos que constantemente desentonan con su alrededor, por lo que tienen que reprimirse en silencio, casi como para pasar desapercibidos y a quienes por norma a la Historia no le interesa abordar. Al mismo tiempo, este tipo de subjetividad coincide con el interés que existe por la reexaminación de la historia a la que alude Juan-Navarro:

One of the greatest efforts of postmodern historians is directed toward breaking the myth of an identity between the past and history. The past is obviously the historian's domain, but such past can only be approached through limited and necessarily inconclusive discursive practices. This critical reonopptualization of history may have a democratizing effect, since it allows even the most marginal sectors to produce and validate their own versions of the past. (47, las cursivas son mías)

Del mismo modo, Cielos de la Tierra es un esfuerzo por parte de sus personajes-narradores por transmitir una historia marginal y excéntrica ${ }^{8}$ por ser ésta más íntima, personal y más humana. Es por

\footnotetext{
${ }^{8}$ Ex-céntrico en el sentido que lo utiliza Hutcheon, es decir, alejado del centro 0 en las márgenes.
} 
ello que si Hernando nos dice o no la verdad, ya no es relevante. Lo que sí es válido es que relata su vida según él desea contarla: "Hay mucho más aquí esperando en el umbral de mi memoria, muchos más hechos de mis años queriendo ser anotados aquí. Bastó que trajera a cuento un primer recuerdo para que todos los demás vinieran a reunírseme" (119).

También, los personajes de Cielos de la Tierra, no podrían ser más comunes y ordinarios. Un indio franciscano del siglo dieciséis, una burguesa con inclinaciones de izquierda en las postrimerías del siglo veinte, y una habitante del futuro que enfrenta la pérdida del lenguaje, son los desiguales discursos que pueblan la novela. Y todos juntos conforman la voz autoral que revisita el pasado, examina el presente y pretende cambiar el futuro.

Cada uno de ellos reafirma su identidad al denunciar sus diferencias, y paradójicamente, cada uno de ellos se afianza a su entorno al entregarse y hasta abandonarse al oficio de la escritura. Sus historias personales encuentran validación en el plano de la novela inventada por Boullosa. Sus vidas son las microhistorias que propone Foucault ${ }^{9}$ y que a nadie le atraen. Boullosa narra los hechos que ella misma confecciona, y los cuales tienen como trasfondo datos históricos verdaderos, pero los cuales se subordinan a la invención, al artificio. Este tipo de ficción histórica posmoderna, apunta Juan-Navarro "could very well constitute what some critics have identified as a 'postmodernism of resistance' " (285). 0 lo que desde siempre se ha conocido como el carácter subversivo o contestatario de la obra de arte.

Por último llegamos al apartado de la utopía, o mejor dicho, el fin de la misma. Este tema resulta controversial, pues si para JuanNavarro el anhelo utópico continúa vigente en la narrativa posmoderna, Linda Hutcheon sostiene lo contrario: "There is little of the Utopian in the postmodern, given the lessons of the past.

${ }^{9}$ Juan-Navarro en A rchival Reflections habla de las microhistorias propuestas por Foucault como una herramienta del revisionismo histórico (48-49). 
This is what many find depressing about postmodernism, and perhaps rightly so" (A Poetics of Postmodernism 215). D entro de la condición posmoderna, la ineficacia de las metanarrativas han propiciado también el abandono del pensamiento utópico, y Cielos de la Tierra no es la excepción. Como típico autor contemporáneo, Boullosa no sitúa su utopía en una isla o un lugar imaginado, sino en el futuro, en la supervivencia de los tiempos más allá del lenguaje y la memoria.

Si decimos coincidir con Hutcheon, en cuanto a que la posmodernidad presencia el fin de la utopía, nos encontramos en efecto con que el libro de Boullosa es una distopía, puesto que los Cielos de la Tierra se asemejan más bien a una especie de limbo existencial. Lear explica: "Vivimos suspendidos en la atmósfera de la Tierra, alejados de la superficie, evitando las radiaciones, las ruinas, la destrucción, las tolvaneras y nubes tóxicas de las tormentas" (16). Lear y los otros sobrevivientes viven prisioneros en una comunidad intangible y abstracta: "Todo es de aire aquí. [...] La nuestra es materia de aire y como el aire es incorpórea" (17). Su idílico "paraíso" es más bien una especie de purgatorio que obliga a deambular a sus habitantes entre vientos inmateriales, incapaces de recordar, condenándolos eventualmente al olvido total: “Q ue sólo debemos atender al futuro, que es una necesidad imperiosa olvidar el pasado porque fue únicamente lección de errores, porque en él se edificó la destrucción de la naturaleza" (18).

Lo anterior, aunado a la renuncia al lenguaje, hace que la distopía alcance dimensiones catastróficas, pues sin la lengua y el pasado, nada queda ya: "Yo describí en este mismo archivo la importancia de la memoria, pero no imaginé que su pérdida total tuviera esta repercusión: ya nada tiene repercusión" (323). El lamento de Lear es el lamento de la superviviente de su tiempo, pero también podría ser el lamento de los que no tienen voz, aquellos a quienes la Historia les ha negado un lugar y el lenguaje los ha excluido. A Hernando la distopía le resulta bastante familiar; él, conocedor de tres idiomas (náhuatl, castellano y latín), está plenamente consciente de la jerarquía que cada uno de ellos ocupa, y sabe que para no quedar 
relegado al olvido, tendrá que sacrificar su lengua indígena, pero al hacerlo también desparecerá toda su raza.

Como se menciona arriba, Juan-Navarro difiere de Hutcheon en relación con la utopía. Para él, en novelas como Terra N ostra, M umbo Jumbo y L ibro de Manuel, la dimensión utópica "manifests itself in a vision of the Americas as a laboratory in which the postmodern writer experiments with new projects as a force for change" (272). En el caso de Cielos de la Tierra, la utopía consiste en el sincretismo histórico y cultural que los tres personajes representan, pero es Lear quien mejor lo expone. Para ella la quimera radica en la fusión de la historia, la memoria y el lenguaje. Un gran imaginario donde coexistan los tres personajes que representan a tres Méxicos:

Los tres perteneceremos a distintos tiempos, nuestras memorias serán de tres distintas épocas, pero yo conoceréla de Hernando y Hernando conocerá la mía, y ganaremos un espacio común en el que nos miraremos a los ojos y formaremos una nueva comunidad. La nuestra se llamará L os Cielos de la Tierra. L'A tlàntide pertenecerá al pasado, como la vieja Tenochtitlan, como el México de Hernando y el país de Estela. (369)

Hernando, Estela y Lear no sólo son producto de tres épocas e idiosincrasias distintas, sino que los tres son protagonistas subversivos que buscan hacer oír su voz en la sociedad. Hernando anhela un sentimiento de pertenencia. Agobiado ante el choque de la conquista, humillado por su condición indígena en el nuevo orden social, pero armado de su conocimiento del lenguaje, él se rebela ante su estatus al asumir el rol agencial de narrador y transmitirnos su historia. Por su parte, Estela oculta el manuscrito de Hernando; insegura del destino que éste tendrá, decide quedárselo para sí y descifrar por medio de la paleografía ese otro universo que irrumpe en el suyo. A simismo, Lear, quien es testigo de la destrucción total, va en contra de todas las ordenanzas de L'A tlàntide con tal de recuperar lo que para ella salvará su comunidad del oscurantismo. Todos ellos asumen un papel contestatario por ir en contra de las 
normas, las instituciones y las leyes. Al defender la escritura, estos personajes-autores defienden a la humanidad de la ignorancia y la barbarie. Según cita Juan-Navarro en su libro: "According to Doctorow, the moral obligation of the fiction writer today is to struggle in order to restore fiction to its former utopian condition" (273). Y es precisamente este papel que Boullosa adopta al advertir al lector de la tragedia que puede sobrevenirse de perderse la memoria y el lenguaje, ya que sin éstos, las utopías ya no son posibles y el futuro ya no es avistable.

A lo largo de este estudio se han analizado los rasgos posmodernos de la metaficción, la historiografía, la subjetividad y la utopía. El universo de la novela de Boullosa nos ha permitido observar cómo se manifiestan estos elementos al analizar tres entidades que forman parte de una unidad. Hernando, Estela y Lear, por disímiles que sean, comparten la necesidad de salvar la memoria, la Historia y la utopía. Los tres personajes llevan a cabo su labor por medio de la escritura, y desde diferentes espacios, épocas e idiomas logran crear un texto dialógico que se resume en el aviso profético de Lear: "Salvaremos al lenguaje y a la memoria del hombre, y un día conformaremos al puño que nos relate. [...] Un abismo estará abierto a nuestros pies. É sos serán los cielos de la Tierra" (369).

Sin embargo, el libro de Boullosa no es un texto cerrado ni jerarquizante, sino uno que obliga al lector a engancharse por completo en su lectura, y que exige un compromiso de participación en el que el lector deberá sortear todos los obstáculos que la autora (intencionalmente 0 no) le pone, como la complejidad de la estructura que conlleva la multiplicidad de voces narrativas, pasando por el cambio de tiempos, hasta los motivos ulteriores de sus personajes de reclamar su lugar en la Historia. Al respecto, Hutcheon apunta: "The theory and practice of postmodern art has shown ways of making the different, the off-center, into the vehicle for aesthetic and even political consciousness-raising-perhaps the first and necessary step to any radical change" (A Poetics 73). Si los tres personajes excéntricos y contestatarios de Cielos de la Tierra representan un paso más hacia la representatividad, encontrando un foro en 
el espacio de la novela posmoderna, podríamos entonces concluir que en un futuro sus discursos trascenderán el campo de la ficción para situarse en el de la realidad. Tal vez ésos sean los cielos de la Tierra de los que habla Boullosa. Tal vez ésa sea la utopía de la condición posmodema.

\section{Bibliografía}

Beverley, John, José Oviedo y Michael Arona (eds.). The Postmodernism D ebate in L atin A merica. D urham: D uke University Press, 1995.

Boullosa, Carmen. Cielos de la Tierra. México: Alfaguara, 1997. Hutcheon, Linda. A Poetics of Postmodernism: H istory, Theory, Fiction. Nueva York: Routledge, 1988.

Jameson, Frederic, The Postmodern Condition: A Report on Knowledge, 1979. Prefacio de Jean-François Lyotard. Trad. G eoff Bennington y Brian Massumi. Minneapolis: University of Minnesota Press, 1999. vii-xxi.

Juan-Navarro, Santiago. A rchival Reflections: Postmodern Fiction of the A mericas (Self- Reflex ivity, H istorical Revisionism, U topia). Cranbury, N. J.: Associated University Presses, 2000.

Leitch, Vincent B. TheN orton A nthology of Theory and Criticism. Nueva York: W. W. Norton \& Company, 2001.

Lyotard, Jean-François. "D efining the Postmodern" (Leitch 16121615).

The Postmodern C ondition: A Report on Knowledge. 1979. Trad.

Geoff Bennington y Brian Massumi. Minneapolis: University of Minnesota Press, 1999.

Williams, Raymond L. The Postmodern N ovel in L atin A merica: Politics, Culture, and the Crisis of Truth. Nueva York: St. Martin's Press, 1996. 